\title{
Management to improve neonate piglet survival
}

\author{
Claudio Oliviero \\ Department of Production Animal Medicine, Faculty of Veterinary Medicine, University of Helsinki, \\ Paroninkuja 20, 04920 Saarentaus, Finland.
}

\begin{abstract}
In the recent years the use of hyper-prolific sows has increased and litters with more than 14-16 born alive piglets are not uncommon. However, piglets' mortality after birth before weaning can range between 11 to $24 \%$ in several countries. Recent findings show that, without human assistance of piglets (cross fostering, movement to a nurse sow, split- or suckling assistance), sows with an average litter size of $13.5 \pm 0.8$ piglets managed to wean $10.6 \pm 0.6$ piglets (average $\pm S D$ ). This indicates that the upper limit that the domestic sow is capable of taking care till weaning is much lower than the current average total number of piglets born. The average number of weaned piglets obtained in many European countries is possible only with high standards piglets' management practices. In this review, the most recent findings in physiology of new-born piglets and their implication in the management to improve perinatal piglets' survival are described.
\end{abstract}

\section{Introduction}

In the last two decades there has been a clear trend in developing hyper-prolific pig breeds in many countries, which has increased the litter size (Bjerre et al. 2010, Paredes et al. 2012). In order to evaluate the productivity of a sow, it would be best to select for number of piglets weaned. However, due to the common practice of cross fostering small piglets at an early age of life, the number of total piglets born has been preferred as a mean of selection (Su et al. 2007). Litters with more than 16 total born piglets have been associated with higher stillbirth rates (1.5 piglets) than litters of 11-12 total born piglets (0.6 piglet) (Boulot et al. 2008). Comparing similar litter sizes, Canario et al (2006) found the probability of stillborn piglets in large litters to be almost twice as high. Large litters are also associated with longer farrowings, higher risk of hypoxia for piglets during birth (Herpin et al. 2001), and higher within-litter weight variation (Milligan et al. 2002). Piglets' mortality after birth before weaning can range from 11 to $24 \%$ in several countries, and it is mostly concentrated in the first 5 days of life (Pedersen et al. 2011, KilBride et al. 2012). The main causes of death included crushing, low viability, starvation and diseases. These levels of pre-weaning mortality represent a challenge to modern pig production and also an animal welfare concern. The purpose of this review is to summarize the recent findings on physiology of new-born piglets and their implications in the management to improve perinatal piglets' survival.

\section{Physiology of new-born piglets}

Body thermoregulation is a challenging process for neonate piglets. They are born wet covered by foetal fluids, which decreases considerably their skin temperature if they don't dry quickly. 
They are provided with a very little pelage which could reduce body temperature dissipation, and they lack brown fat which could be metabolized to generate heat and balance their body temperature (Berthon et al. 1994). Therefore new-born piglets are very vulnerable to the environmental temperature, and they can display adequate metabolic responses to reduce heat loss only if their body temperature is above $34^{\circ} \mathrm{C}$ (Lossec et al. 1998). Those main metabolic responses are: mobilization of free fatty acids, shivering, and a modest gluconeogenesis using own liver's glycogen reserve. The latter is available and metabolized within a maximum of 1520 hours in starving piglets (Svendsen \& Bengtsson 1986, Lossec et al. 1998). Pedersen et al. (2011) found that piglets with a rectal temperature of $36.1{ }^{\circ} \mathrm{C} 2 \mathrm{~h}$ after birth, had greater odds (0.09) of being crushed by the sow, while for piglets with a rectal temperature of $38.6{ }^{\circ} \mathrm{C}$ the odds were smaller (0.05). Furthermore, Herpin et al. (1996) demonstrated that piglets which suffered from hypoxia (rupture of the umbilical cord or detachment of the placenta) during parturition were less vital, took more time to reach the sow's udder (120 \pm 35 vs $25 \pm 3$ min). They also showed a hampered ability of maintaining the body temperature $(36.3 \pm 0.9$ vs $38.4 \pm 0.1^{\circ} \mathrm{C}$ ) during the first 24 hours of life. In contrast to older animals, the early neonatal piglet does not increase its energy intake in response to cold temperature. Actually, colostrum intake decreases by $36.8 \%$ during a cold exposure $\left(18-20{ }^{\circ} \mathrm{C}\right)$, when compared to piglets at ambient temperature between $30-32{ }^{\circ} \mathrm{C}$, exacerbating the likelihood of starvation (Lay et al. 2002). Kammersgaard et al (2011) found that birth weight over $1.1 \mathrm{~kg}$ was the most important single factor in successful recovery from postnatal hypothermia. In addition, Milligan et al (2002) found that birth weight over $1.3 \mathrm{~kg}$ was positively correlated to higher piglet pre-weaning survival. It has been shown that the birth process and individual characteristics influence the piglet's thermoregulatory mechanism. However, in an environment like the modern farrowing unit, with different zones at different temperatures, it is heat preservation rather than mere heat production that determines thermoregulatory success and recovery from postnatal hypothermia (Kammersgaard et al. 2011).

Because of the epitheliochorial nature of the porcine placenta, the neonate piglets lack of maternal IgG at birth. They must acquire maternal immunoglobulins from ingested colostrum for passive immune protection before they will start to produce own immunoglobulins around 3-4 weeks of age (Rooke \& Bland 2002). However, colostrum is produced only during the first 16-24 hours after parturition starts, and already after the first 6 hours the IgG content in colostrum is halved (Le Dividich et al. 2005). The colostrum intake at the right time frame and amount can be challenged by sibling competition, delayed farrowing time and reduced viability. All these factors have a major impact in large litters (Devillers et al. 2007). The same authors found that individual colostrum intake ranged from 0 to more than $700 \mathrm{~g}$ during the first 19 hours of life (450 g/kg birth weight), indicating that the intake capacity of the piglet can be extremely high when colostrum supply is not restricted. However, in large litters those ad libitum quantities of colostrum are rarely available to all piglets, and probably an amount around 200-250 g consumed per piglet induces a sufficient protection. Devillers et al (2011) found that pre-weaning mortality rate was $7.1 \%$ when piglets ingested more than $200 \mathrm{~g}$ of colostrum and increased to $43.4 \%$ when intake was less than $200 \mathrm{~g}$. It appears that piglets' intake capacity is not the limiting factor for colostrum intake, while the limitation could be found in the sow's colostrum availability, especially in large litters. Colostrum yield is highly variable, it averages $3.3-3.7 \mathrm{~kg}$, ranging from less than $1.5 \mathrm{~kg}$ to more than $6.0 \mathrm{~kg}$ (Devillers et al. 2007, Quesnel 2011). However, Andersen et al (2011) found that without human assistance of piglets (drying, placing under a heat lamp, cross fostering, movement to a nurse sow, split- or suckling assistance), it can be difficult for many sows to adequately nurse more than 10-11 piglets. Furthermore, Quesnel et al (2012) suggest that the genetic selection for 
higher prolificacy is probably one of the major causes for the greater incidence of low vitality and low birth weight piglets. These characteristics are likely to end up in consequent higher mortality due to an inadequate colostrum intake.

\section{Practices to improve neonate piglet survival}

Once piglets are born the farmers need to quickly implement a strategy to reduce piglet mortality. This is important especially in large litters in which chances to have low viable piglets, competition for colostrum and milk access are higher (Lund et al. 2002). Those strategies can vary according to the type of farrowing unit, the availability of workers and the degree of experience. The measures directed to improve neonatal piglet survival can be divided in three areas of action: environment, sow, and piglets.

\section{Environment}

According to the existing literature, during the first 1-3 days of life crushing accounts between $20-43 \%$ of perinatal mortality of piglets (Tubbs et al. 1993, Edwards 2002). Activity level, lying down and rolling, of loose-housed sow has been found to affect piglets' crushing (Wechsler \& Hegglin, 1997). This is one of the reasons why the farrowing crate, which accommodates the sow before parturition till weaning, is the most commonly used type of housing (70-83\%) during farrowing and lactation period (Johnson \& Marchant-Forde, 2009). However, the reduced crushing rate in crate systems when compared to free farrowing systems has been questioned in some studies (Phillips and Fraser 1993, Cronin et al. 2000). Moreover, restraining sows in crates before parturition may prevent normal movement and expression of natural mothering behaviour, such as nest building (Damm et al. 2000). There is some evidence that crated sows not allowed to perform nest building behaviour, using adequate substrate like straw or saw dust, showed an average increase of $93 \mathrm{~min}$ in farrowing duration and a $4.7 \%$ rise in stillbirth rate, compared to sows in pen with available substrate (Oliviero et al. 2008 \& 2010). Mousten et al. (2012) found the highest piglet survival among sows that farrowed freely and were crated for 4 days after the end of farrowing, compared to sows loose-housed before farrowing and for the whole lactation. Presence of bedding like straw and sawdust at farrowing can be beneficial also for neonate piglets to maintain their body temperature. Recent studies show that some piglets may reach the udder within one minute after birth, while many others may spend up to $3 \mathrm{~h}$ from birth to the first successful suckling (Thingnes et al. 2008). During this long time these piglets will suffer from a considerable heat loss that can compromise their survival. Therefore, after piglets are born and in search of the udder, a layer of straw can offer a good insulation from plain concrete or slatted floor (Curtis, 1970). However, straw should be replaced when it has become wet during or after farrowing. In crated pens, with slatted or semi-slatted floors, placing a removable rubber soft mattress behind the sow can decrease chilling of the piglets immediately after birth. If chopped straw is used, the mattress can also help to keep the layer of straw in place on the slats. In order to reduce heat loss, it can be useful to have a creep area in the farrowing pen, which can be equipped with a heat lamp generating a comfortable microclimate for neonate piglets (over the lower critical temperature of $34{ }^{\circ} \mathrm{C}$ ) This allows them to efficiently dry off and regulate their body temperature (Adams et al. 1980). However, neonate piglets seem to be more attracted by the sow's body, other piglets and birth fluids, without going firstly to the warm creep area (Andersen et al. 2007). Some studies found that all causes of mortality (starving, crushing and other causes) were significantly lower when the piglets were placed under the heat lamp / dried immediately after birth compared to piglets that 
were not handled (Christison et al.1997, Andersen et al. 2009). Use of floor heating $\left(33-34{ }^{\circ} \mathrm{C}\right)$ around farrowing resulted in earlier onset of suckling and reduced piglets' mortality rate (7.2\% vs $12.2 \%$ no floor heating) during the first three days of life (Malmkvist et al., 2006) However, housing in those temperatures during lactation could negatively affect the sow reducing the feed intake (McGlone et al. 1988). In contrast, Damgaard et al. (2009) found that floor heating from $12 \mathrm{~h}$ after the onset of nest building behaviour and until $48 \mathrm{~h}$ after birth of the first piglet, compared with no floor heating, did not compromise physiological parameters such as water intake and body temperature in loose-housed sows. Therefore, floor heating seems to be useful in the first days around parturition. Later on, only a warm creep area for piglets would be more beneficial for the sow, and for the piglets which start to make use of creep area more actively from the third day of life on (Vasdal et al. 2009).

Sow

Assuming that the sow has been given the opportunity to properly express the pre-farrowing nest building behaviour, as described in the previous paragraph, the main role of the sow immediately after birth is to produce enough colostrum and milk for the litter. The first thing that should be evaluated at the end of parturition is the correspondence between the number of functioning teats and the number of piglets born alive. Sows of different breeds can have between 12 to 18 teats (Labroue et al. 2001), however not all teats may be active. This is of particular importance in first parity sows. Farmer et al (2012) found that piglets suckling teats that were previously used and functioned in first lactation had a $340 \mathrm{~g}$ of body weight gain advantage from day 2 to day 14 of lactation, compared to piglets which suckled teats not active during the previous lactation. Insufficient colostrum and milk production can affect the whole mammary gland and it is known as postpartum dysgalactia syndrome (PDS). However, in presence of a large litter (>16 piglets), even with a full functioning mammary gland it is often necessary to intervene and ensure an adequate colostrum and milk intake to all piglets. The necessity and importance of human intervention in presence of large litter is confirmed by recent studies in which no manipulation of litter size (cross fostering, movement to a nurse sow), and no human assistance (split- or suckling assistance, drying), determined a constant number of surviving piglets at the time of weaning between 10 and 11 . These findings suggest that this number could be the upper limit that the domestic sow is capable of taking care of (Andersen et al. 2011). The most common strategy, dealing with excess of newborn piglets, is to reallocate them to other sows. However before doing this, an adequate colostrum intake from the own mother should be ensured as described in the following paragraph. One simple way to deal with extra piglets is to cross foster them within litters of piglets born during the same day. This way litters can be evened ensuring that low birth weight piglets compete with litter mates of similar size. This practice reduces the risk of being excluded from the udder by the heavier ones (English, 1998). The competition for teats is even more marked in large litter size. Deen and Bilkei (2004) found that the mortality at weaning of low-birth weight cross fostered piglets (0.9-1.0 kg) was 34.5\% if allocated in large litters (12 piglets) with high-birth weight littermates $(>1.6 \mathrm{~kg})$. When allocated in small litters (8 piglets) with average-birth weight littermates (1.2-1.59 kg) or high-birth weight littermates, the mortality was $16.1 \%$ and 19.6 $\%$, respectively. Cross fostering should therefore be performed during the first day of age, after piglets get adequate colostrum from their own mother. Roberts and Martineau (2001) found that cross-fostering disrupted behavior (more fights, vocalizations, nonproductive nursings) and growth of fostered litters at different ages during lactation (day 4, 7, 10, 13 and 16) except on day 1. Similarly, Price et al. (1994) found that cross fostered piglets were more likely $(P<0.01)$ to be among the last two animals to contact the sow's udder than resident piglets. This occurred 
during milk ejections if fostered at day 2,4 , or 7 of lactation but not on day 1 . However, cross fostering become more and more challenging with increasing of litter size, and other strategies are needed. Recently in some countries, like Denmark, with hyper-prolific pig lines, the use of nurse sows has become common. Nurse sows can be made with a one-step process. This implies weaning a litter of piglets ready to be weaned (usually at 21 days of lactation). The donor sow then receives all the one-day old excess piglets from the sows recently farrowed. The quality of the milk is considered acceptable to the newborn piglets (assumed that they've all got colostrum from their own mothers) However, the nurse sow is used to her own piglets initiating the lactation, being suckled more intensively and being used to more active and older piglets (Jensen et al. 1991). Consequently, she will often have a temporary decrease in her milk production (2-3 days) before turning back to standard levels. Nurse sows can also be made in a two-step process by weaning a litter of piglets ready to be weaned from an "intermediate nurse sow". This sow is supposed to receive piglets of 2 to 7 days of age from another selected sow with a good milk production, which is then ready to receive all one-day old excess piglets. In this way the two-step nurse sow will not have a decrease in milk production, as she is still used to initiate the lactation. Nurse sows should probably be made in a two-step process if the objective is to move one-day old piglets to them. However in both processes, no more of the same amount of piglets removed from the nurse sow should be collected and moved to her from the other sows. The extra piglets to be chosen for transfer to the nurse sow should be the bigger among the litters, because they stimulate the nurse sow's udder better and will create a more uniform new litter.

Piglets

As described previously, neonate piglets are challenged to keep their body temperature over their functional level of $34^{\circ} \mathrm{C}$. Therefore a great effort should be put to quickly dry them off soon after birth and place them in an adequate microclimate minimizing their body heat loss. A second important step is to provide the whole litter with a sufficient individual colostrum intake (200-250 g) within 12-16 hours from the beginning of parturition (Devillers et al. 2011). When possible, small and low viable piglets should be assisted to suckle, helping them to attach to the teat, ensuring that colostrum is ingested. It is important to remember that small piglets have difficulties to suckle from big teats, therefore the smallest functioning teats should be preferred when assisting suckling. This procedure should be repeated 3-4 times within the first few hours if those piglets are not seen actively suckling. Additionally, low viable piglets can be hand fed with colostrum collected from their own mother or other sows within 6-12 hours from beginning of farrowing. At this phase, milking by hand is relatively easy, due to almost continuous (every 5-40 min) milk ejections (Algers \& Uvnäs-Moberg 2007). Piglets can be hand fed using a feeding bottle with a suitable nipple or using a syringe connected to a soft silicone plastic tube (3-4 mm in diameter) to insert in the oesophagus till the piglet's stomach and allowing $20-25 \mathrm{ml}$ of colostrum. To estimate the right length of the part of the tube to introduce in the piglet's mouth till the stomach, the tube can be previously marked with the distance from the edge of the nose to the last rib on the chest of the piglet. Particular care should be taken to avoid wrong positioning of the tube in the trachea or injuries of the larynx. Assisted suckling and hand feeding work well in small to normal litters with only one or two small piglets. In large litters and more low viable piglets, a split suckling strategy could be more effective. In order to minimize the sibling competition for colostrum intake, the litter is split in two groups. The heavier and stronger piglets are kept in the creep area or in a separate box, allowing the smaller piglets to suckle for 60-90 minutes, and then the groups are switched. When separating the piglets, both groups should always have free access to a warm creep area. 
This can be easily obtained using a box with an additional heat lamp for the separated group, which leaves the creep area accessible for the remaining group to suckle. If some small piglets are still not able to successfully suckle, assisted suckling should be combined with split suckling.

\section{Concluding remarks}

Here are listed the most important management procedures to improve neonatal piglet survival.

- Provide sow with a substrate (like straw) 1-2 days before the start of parturition, in a free farrowing space when possible.

- Measures to reduce piglets' body heat loss include: presence of bedding material on the floor (straw, sawdust) to be replaced when wet, removable rubber mattress on slatted floor, floor heating, a creep area with a heat lamp, promptly dry and place new-born piglets in adequate microclimate $\left(34^{\circ} \mathrm{C}\right)$.

- Evaluate teat functionality and whether functioning teats are in accordance with the number of piglets born.

- Ensure colostrum intake to all piglets in the litter by assisting suckling, hand feeding and split suckling.

- Cross foster piglets during their first day of life, levelling the litters by weight.

- Use nurse sows to rear excess piglets of several large litters.

\section{References}

Adams K, Baker T \& Jensen A 1980. Effect of Supplemental Heat for Nursing Piglets. Journal of Animal Science 50 779-782.

Algers B \& Uvnäs-Moberg K 2007. Maternal behavior in pigs. Hormones and Behavior 52 78-85.

Andersen I, Tajet G, Haukvik I, Kongsrud S and Boe K 2007. Relationship between postnatal piglet mortality, environmental factors and management around farrowing in herds with loose-housed, lactating sows. Acta Agriculturae Scandinavica Section A 57 38-45.

Andersen I, Haukvik I \& Bøe K 2009. Drying and warming immediately after birth may reduce piglet mortality in loose-housed sows. Animal 3 592-597

Andersen I, Nevdal E \& Bøe K 2011. Maternal investment, sibling competition, and offspring survival with increasing litter size and parity in pigs (Sus scrofa). Behavioral Ecology Sociobiology 65 1159-1167.

Berthon D, Herpin P \& Le Dividich J 1994. Shivering thermogenesis in neonatal pig. Journal of Thermal Biology 19 413-418.

Bjerre D, Mark T, Sorensen P, Proschowsky H, Vernersen A, Jorgensen C \& Fredholm M 2010 Investigation of candidate regions influencing litter size in Danish Landrace sows. Journal of Animal Science $\mathbf{8 8}$ $1603-1609$.

Boulot S, Quesnel H \& Quiniou N 2008. Management of High Prolificacy in French Herds: Can We Alleviate Side Effects on Piglet Survival? Advances in Pork Production 19 1-8.

Canario L, Cantoni E, Le Bihan E, Caritez J, Billon Y, Bidanel J \& Foulley J 2006. Between-breed variability of stillbirth and its relationship with sow and piglet characteristics. Journal of Animal Science 84 31853196.

Christison G, Wenger I \& Follensbee M 1997. Teat seeking success of newborn piglets after dying or warming. Canadian Journal of Animal Science 77 317-319.

Cronin G, Lefébure B \& McClintock S 2000. A comparison of piglet production and survival in the Werribee farrowing Pen and conventional farrowing crates at a commercial farm. Australian Journal of Experimental Agriculture 40 17-23.

Curtis S 1970. Environmental-thermoregulatory interactions and neonatal piglet survival. Journal of Animal Science 31 576-587

Damgaard B, Malmkvist J, Pedersen L, Jensen K, Thodberg K, Jørgensen E \& Juul-Madsen H 2009. The effects of floor heating on body temperature, water consumption, stress response and immune competence around parturition in loose-housed sows. Research in Veterinary Science 86 136-145.

Damm B, Vestergaard K, Schrøder-Petersen D \& Ladewig J 2000. The effects of branches on prepartum nest building in gilts with access to straw. Applied Animal Behaviour Science 69 113-124.

Deen M \& Bilkei G 2004. Cross fostering of low-birthweight piglets. Livestock Production Science 90 279-284.

Devillers N, Farmer C, Le Dividich J \& Prunier A 2007. Variability of colostrum yield and colostrum intake in swine. Animal 11033-1041.

Devillers N, Le Dividich J \& Prunier A 2011. Influence 
of colostrum intake on piglet survival and immunity. Animal 5 1605-1612.

Edwards S 2002. Perinatal mortality in the pig: environmental or physiological solutions? Livestock Production Science 78 3-12 .

English P 1998. Ten basic principles of fostering piglets. Pig Progress 14 39-41.

Farmer C, Palin MF, Theil P, Sorensen M \& Devillers N 2012. Milk production in sows from a teat in second parity is influenced by whether it was suckled in first parity. Journal of Animal Science 90 3743-3751.

Herpin P, Le Dividich J, Fillaut C, De Marco F \& Bertin R 1996. Effects of the level of asphyxia during delivery on viability at birth and early postnatal vitality of newborn pigs. Journal of Animal Science 74 2067-2075.

Herpin P, Hulin JC, Le Dividich J \& Fillaut M 2001. Effect of oxygen inhalation at birth on the reduction of early postnatal mortality in pigs. Journal of Animal Science 79 5-10.

Jensen P, Stangel G \& Algers B 1991. Nursing and suckling behaviour of semi-naturally kept pigs during the first 10 days postpartum. Applied Animal Behaviour Science 31 195-209.

Johnson A \& Marchant-Forde J 2009. Welfare of pigs in the farrowing environment. In The welfare of pigs pp. 141-188. Ed. Marchant-Forde J. The Netherlands: Springer.

Kammersgaard T, Pedersen L \& Jørgensen E 2011. Hypothermia in neonatal piglets: Interactions and causes of individual differences. Journal of Animal Science 89 2073-2085

KilBride A, Mendl M, Statham P, Held S, Harris M, Cooper S \& Green L 2012. A cohort study of preweaning piglet mortality and farrowing accommodation on 112 commercial pig farms in England. Preventive Veterinary Medicine 104 281- 291.

Labroue F, Caugant A, Ligonesche B \& Gaudré D 2001. Étude de l'évolution des tétines dápparence douteuse chez la cochette au cours de sa carrier. Journées de la Recherche Porcine en France 33 145-150.

Lay D, Matteri R, Carroll J, Fangman T \& Safranski T 2002. Preweaning survival in swine. Journal of Animal Science 80 74-86.

Le Dividich J, Rooke J \& Herpin P 2005. Review: nutritional and immunological importance of colostrum for the newborn pig. Journal of Agricultural Science 143 469-485.

Lossec G, Herpin P \& Le Dividich J 1998. Thermoregulatory responses of the newborn pig during experimentally induced hypothermia and rewarming. Experimental Physiology 83 667-678.

Lund M, Puonti M, Rydhmer L \& Jensen J 2002. Relationship between litter size and perinatal and preweaning survival in pigs. Animal Science 74 217-222.

Malmkvist J, Pedersen L, Damgaard B, Thodberg K, Jorgensen E \& Labouriau R 2006. Does floor heating around parturition affect the vitality of piglets born to loose housed sows? Applied Animal Behaviour Science 99 88-105

McGlone J, Stansbury W \& Tribble L 1988. Management of lactating sows during heat stress: Effects of water drip, snout coolers, floor type, and a high energy-density diet. Journal of Animal Science 66 885-891.

Milligan B, Fraser D \& Kramer D 2002. Within-litter birth weight variation in the domestic pig and its relation to pre-weaning survival, weight gain, and variation in weaning weights. Livestock Production Science $\mathbf{7 6}$ 181-191.

Moustsen V, Hales J, Lahrmann H, Weber P \& Hansen C 2012. Confinement of lactating sows in crates for 4 days after farrowing reduces piglet mortality. Animal 29 1-7.

Oliviero C, Heinonen M, Valros A, Hälli O \& Peltoniemi O 2008. Effect of the environment on the physiology of the sow during late pregnancy, farrowing and early lactation. Animal Reproduction Science 105 365-377.

Oliviero C, Heinonen M, Valros A \& Peltoniemi O 2010. Environmental and sow-related factors affecting the duration of farrowing. Animal Reproduction Science 119 85-91.

Paredes S, Jansman A, Verstegen M, Awati A, Buist W, Den hartog L, Van hees M, Quiniou N, Hendriks W \& Gerrits W 2012 Analysis of factors to predict piglet body weight at the end of the nursery phase. Journal of Animal Science 903243 - 3251.

Pedersen L, Berg P, Jørgensen G \& Andersen I 2011. Neonatal piglet traits of importance for survival in crates and indoor pens. Journal of Animal Science $\mathbf{8 9}$ 1207-1218.

Phillips P \& Fraser D 1993. Developments in farrowing housing for sows and litters. Pigs News Info 14 51-55.

Price E, Hutson G, Price M \& Borgwardt R 1994. Fostering in swine as affected by age of offspring. Journal of Animal Science 72 1697-1701.

Quesnel H 2011. Colostrum production by sows: variability of colostrum yield and immunoglobulin G concentrations. Animal 5 1546-1553.

Quesnel H, Farmer C \& Devillers N 2012. Colostrum intake: Influence on piglet performance and factors of variation. Livestock Science 146 105-114.

Robert S \& Martineau GP 2001. Effects of repeated cross-fosterings on preweaning behavior and growth performance of piglets and on maternal behavior of sows. Journal of Animal Science 79 88-93.

Rooke J \& Bland I 2002. The acquisition of passive immunity in the new-born piglet. Livestock Production Science 78 13-23.

Su G, Lund M \& Sorensen D 2007 Selection for litter size at day five to improve litter size at weaning and piglet survival rate. Journal of Animal Science 85 1385-1392.

Svendsen L \& Bengtsson A 1986. Reducing perinatal mortality in pigs. In Diseases of swine, edn 6, pp 813825. Eds Leman A, Straw B \& Glock R. USA: lowa University Press.

Thingnes S, Andersen I, Torsethaugen Kand \& Pedersen L 2008. Nursing quality in sows and piglet mortality - preliminary results on the effects of a high and low breeding value for survival rate and two different farrowing environments. Proceedings of the 18th Nordic Symposium of the International Society for Applied Ethology, 16-18 January, Oscarsborg, Norway. 
Tubbs R, Hurd H, Dargatz D \& Hill G 1993. Preweaning morbidity and mortality in the United States swine herds. Swine Health and Production 1 21-28.

Vasdal G, Andersen I \& Pedersen L 2009. Piglet use of creep area - effects of breeding value and farrowing environment. Applied Animal Behaviour Science 120 62-67.
Wechsler B \& Hegglin D 1997. Individual differences in the behaviour of sows at the nest-site and the crushing of piglets. Applied Animal Behavioural Science 51 39-49. 